\title{
Fracture of a Paper Manufacturing Machine Felt Guide Roll
}

\author{
Tim A. Jur $\cdot$ R. Dean Harris
}

Submitted: 31 March 2014/Published online: 4 July 2014

(C) ASM International 2014

\begin{abstract}
A paper manufacturing machine experienced an in-service fracture of one of the machine's felt guide rolls. An engineering analysis of the fractured roll was conducted to determine the cause. Consideration was given to resonant vibration of the roll with respect to operation of the machine at or near the natural frequency of the roll. However, analysis demonstrated that vibration was not an issue. Rather, the roll fracture was attributed to a high cycle fatigue fracture mechanism associated with a plug weld at a threaded fastener used to attach a large balance weight to the inside of the roll. The balance weight was, in turn, installed to compensate for variation in the wall thickness of a pipe product used to make the roll. The cause of the roll fracture was defective manufacture.
\end{abstract}

Keywords Fracture - Fatigue $\cdot$ Seamless pipe .

Critical speed $\cdot$ Stress concentration

\section{Introduction}

The fractured part of concern is a long, slender roll that was located in the dryer section of a paper manufacturing machine. Paper machines are very large pieces of equipment that route the cellulose product as it becomes paper along a continuous felt belt over a series of multiple rolls.

Figure 1 shows the involved paper machine dryer section in schematic form, depicting both dryer rolls and felt guide rolls. Guide rolls serve to hold the felt up against the surfaces of the dryer rolls. It was one of the felt guide rolls

T. A. Jur $(\bowtie) \cdot$ R. D. Harris

Engineering Design \& Testing Corp., Columbia South Carolina

District Office, Cayce, SC, USA

e-mail: tajur@edtengineers.com that fractured. The fracture of this roll not only shut down the machine but also damaged the belt, damaged multiple of the dryer rolls, and damaged other felt guide rolls in the vicinity. The frame of the machine was also damaged.

Figure 2 is a sketch depicting a felt guide roll in operation showing the length of the roll, the width of the felt belt as it passes over the roll, and the nominal cross-sectional dimensions of the roll. The guide rolls themselves are manufactured from what would otherwise be seamless carbon steel pipe. The governing standard for this product is ASTM A106, "Standard Specification for Carbon Steel Pipe for High Temperature Service" [1]. This standard addresses material chemistry as well as mechanical properties. The standard also addresses permissible variations in wall thickness.

As a pipe product, variations in wall thickness are not as critical as when the pipe is to be used as a roll. In operation, the felt belt on the machine of interest traveled at a speed of $3100 \mathrm{ft} / \mathrm{min}(946 \mathrm{~m} / \mathrm{min})$. At this belt speed and for a roll outside diameter of $15.94 \mathrm{in}$. (404.9 mm), the roll is turning at 743 revolutions/minute (rpm). Balancing is now an issue. Steps need to be taken to compensate for varying wall thickness, recognizing that the wall thickness of seamless pipe product will not be uniform.

\section{Description of the Fractured Roll}

Figure 3 shows the fracture location on the roll, the fracture having occurred 70 in. $(1778 \mathrm{~mm})$ from one end. Figure 4 shows the fracture surface at the "short end" of the roll. Of particular interest is a block of steel identified by an arrow in Fig. 4 that had been attached to the inside wall of the roll to compensate for the circumferential variation in roll weight due, in turn, to the variation in the wall thickness. 
Fig. 1 Schematic drawing of paper machine dryer section showing notes from actual inspection; large diameter rolls are dryer rolls; small diameter rolls are felt guide rolls
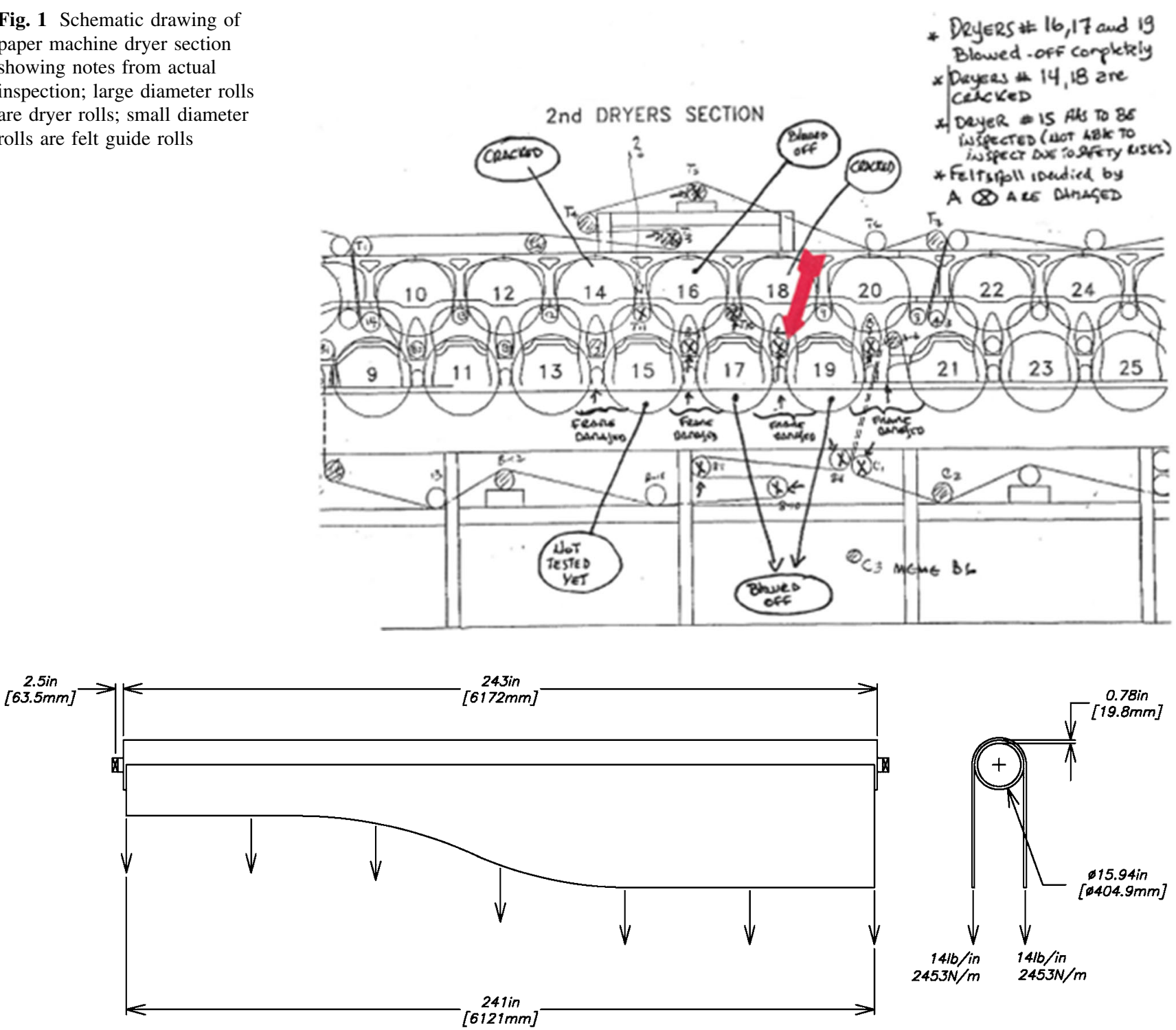

Fig. 2 Schematic drawing of felt guide roll in operation, showing nominal dimensions

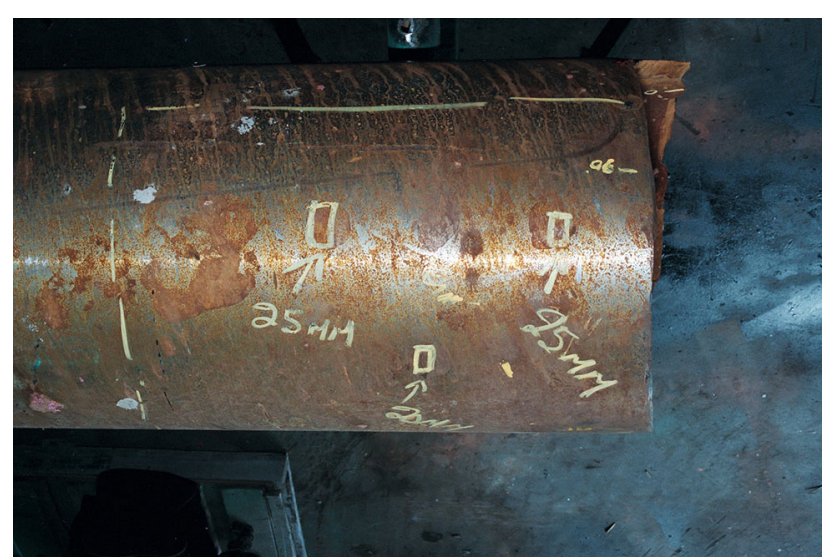

Fig. 3 Fractured end of roll, located 70 in $(1778 \mathrm{~mm})$ from one end

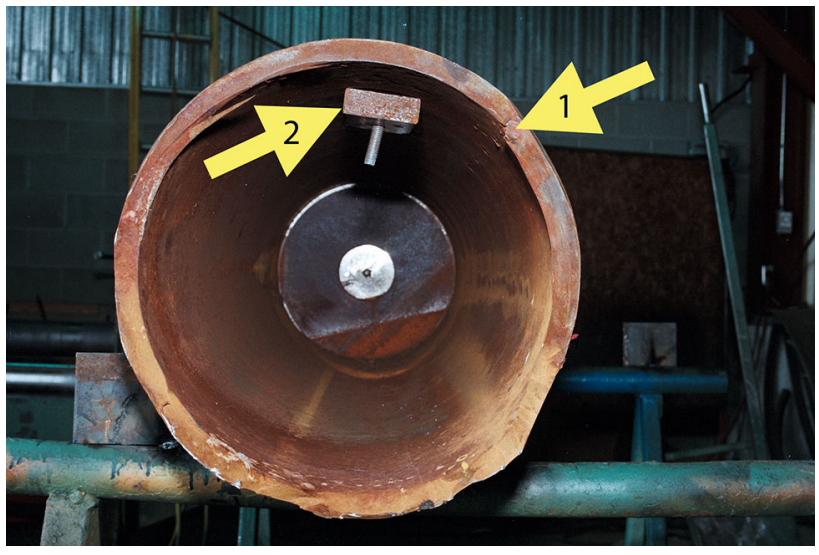

Fig. 4 Fracture surface; short end of roll; Arrow 1 points to fracture origin; Arrow 2 points to balance weight 


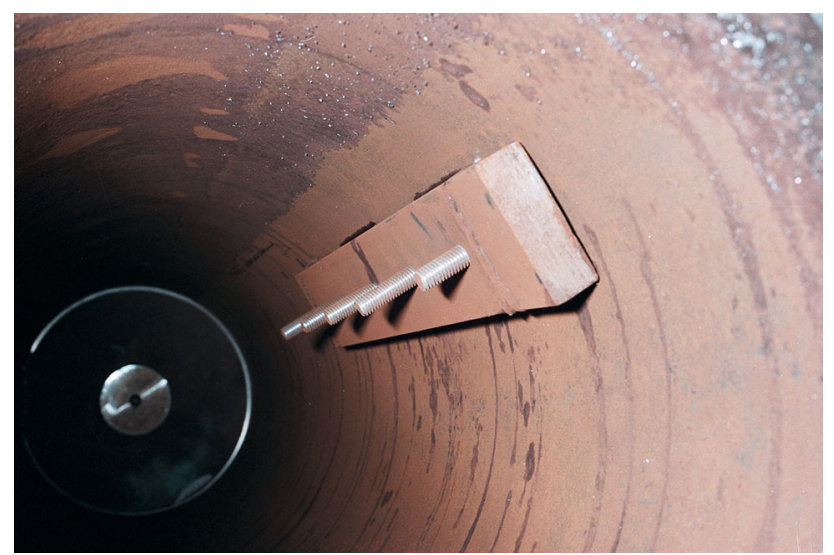

Fig. 5 Another balance weight installed on long end of fractured roll

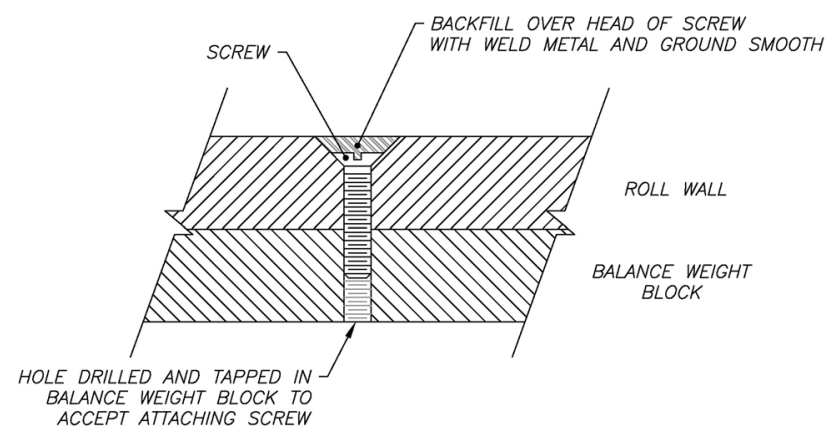

Fig. 6 Sketch showing manner by which balance weight attached to roll wall

This block (this balance weight) is attached at or near where the roll wall is the thinnest. Figure 5 shows yet another balance weight attached to the inside wall of the "long end" of the fractured roll. Measurements confirmed the wall thickness to vary from 0.938 in. $(23.825 \mathrm{~mm})$ to 0.688 in. $(17.475 \mathrm{~mm})$. Although the variation is quite large (36\% of smaller dimension), the variation in wall thickness is within that allowed by the pipe material specification, A106.

Figure 6 shows the manner in which balance weights were attached to the roll. The installation involved drilling and countersinking holes in the roll wall. Flathead screws were then run through the holes to fasten the weights against the roll inside surface. The holes drilled in the roll wall to accept the machine screws were countersunk to a sufficient depth such that a shallow hole existed at each screw head. The shallow holes were backfilled with weld metal and ground smooth. There was no effort taken to stress relieve the weld location.

The characteristic features of the fracture surface (Fig. 4) were such that it was evident that the roll fractured in fatigue. A close-up of the fracture origin is shown in Fig. 7. It is apparent that the origin involved one of the screw insert locations. Shown in Fig. 8 is the balance

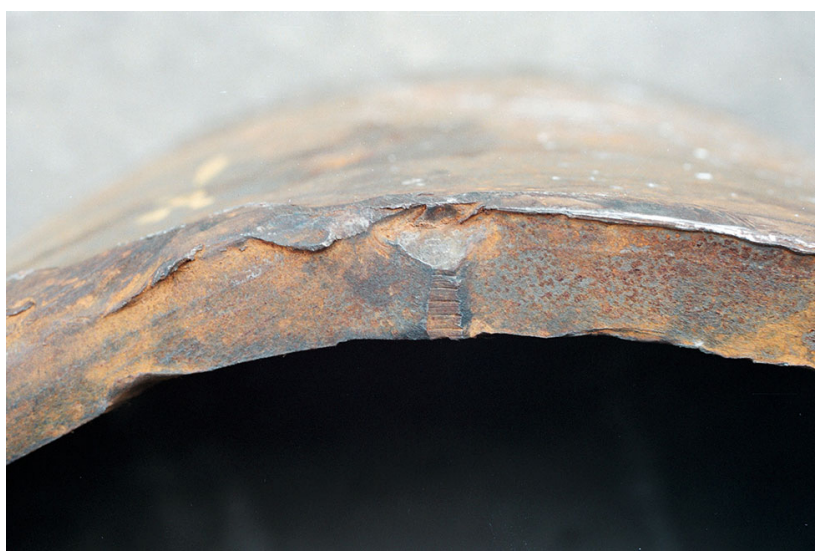

Fig. 7 Close-up of fracture origin (see Arrow 1, Fig. 4)

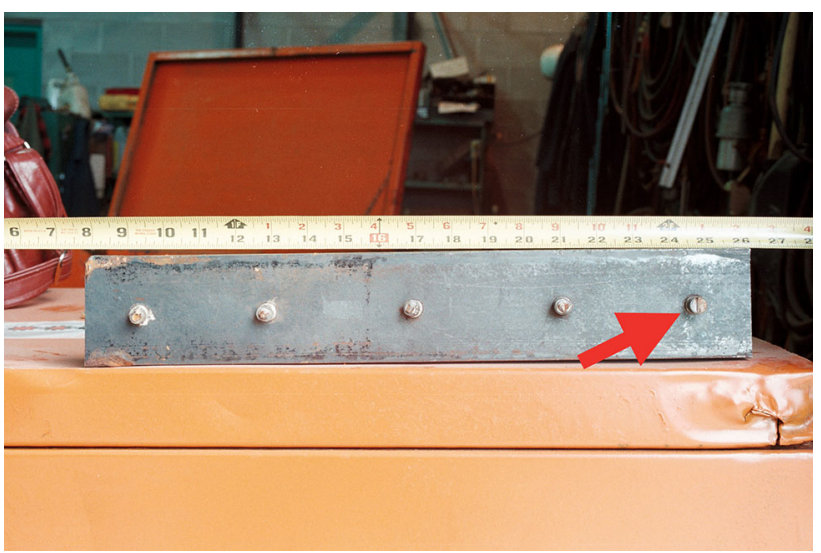

Fig. 8 Balance weight that had been installed on short end of fractured roll; Arrow points to fractured screw originally located at origin of fracture

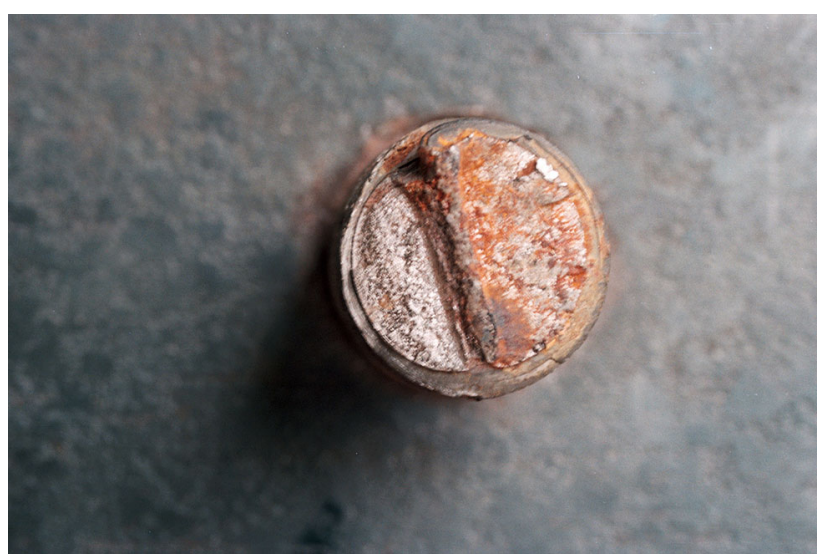

Fig. 9 Close-up of fracture surface of screw identified by Arrow in Fig. 8

weight that had been attached to the roll and that involved the screw insert that was the origin of the fatigue fracture. All five attaching screws were found fractured. The weight was found to have dropped loose and away from its 


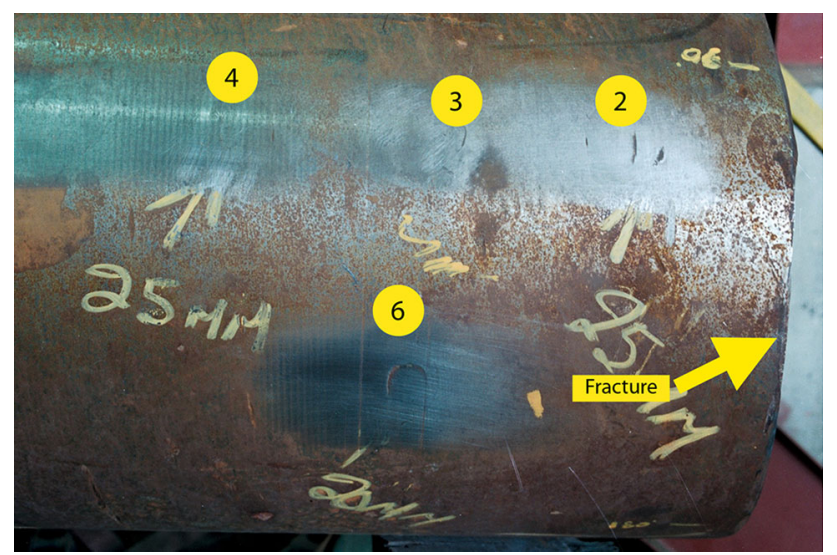

Fig. 10 Short end of fractured roll with surface of roll cleaned to reveal cracks developed at other locations where screws placed to install balance weights

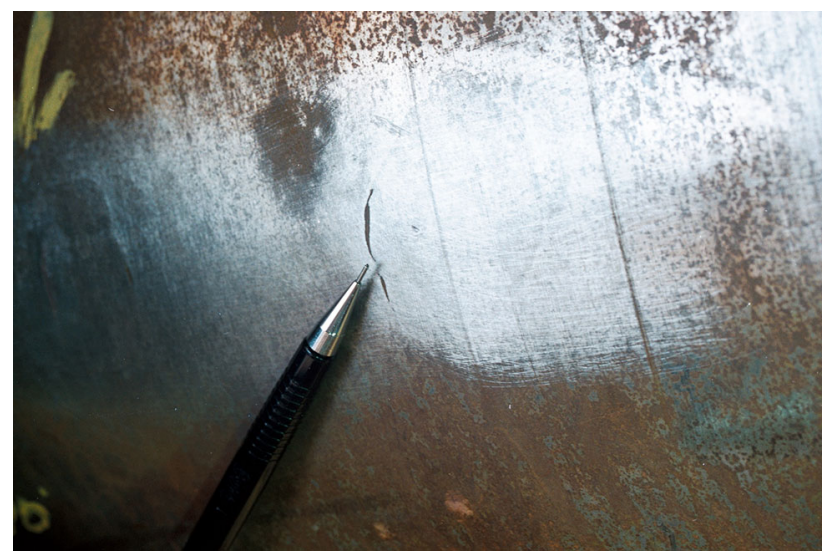

Fig. 11 Close-up of one of crack locations identified in Fig. 10

attached position when the roll was examined after the fracture. The arrow in Fig. 8 points to the fractured screw that had been located at the origin of the roll fracture. A close-up of the fracture surface of this screw is shown in Fig. 9. This screw fractured in fatigue, as did the other four screws that had been holding the balance weight in place.

Figure 10 shows once again the short end of the roll with roll surface now partially cleaned for further observation. The arrow in the figure points to the fractured end and specifically to the point of fracture initiation where the balance weight screw had been located. Locations 2,3 , and 4 are the aligned positions of three of the additional four screws that had been securing the balance block. Location 6 is the place position of yet another screw securing another balance block installed nearby (see Fig. 4 where this additional balancing weight is shown to be still attached). Each of Locations 2, 3, 4, and 6 display developing fatigue cracks. A close-up view of one of these locations is shown in Fig. 11.
Given the seriousness of the fracture of this roll, the objective was to identify the circumstances that resulted in the fracture and, thereupon, determine the cause.

\section{Roll Balance Condition and Critical Speed}

In analyzing the fracture of the roll, it was recognized that, given the non-uniformity of the wall of the pipe product and, therefore, an accompanying circumferential variation in weight, the practice in the paper roll manufacturing industry has been to add compensating balance weights as shown in Figs. 4 and 5. The object in adding the weights is to align the axis of rotation of the roll with its principle axis of inertia. The principle axis of inertia of a body, such as this roll, is a function of its mass distribution. Hence, the attachment of balance weights to the inside wall. Fine tune balancing involves placement of small weights at each end of the roll. With the masses of these weights and/or their radial positions selected in the appropriate manner, a roll is balanced $[2,3]$.

It is known that the roll that fractured was ordered along with several other, identical rolls by the mill at the same time. These rolls were first balanced by the manufacturer at $1080 \mathrm{rpm}$. Upon receipt by the mill, the rolls were rebalanced at $840 \mathrm{rpm}$. Recall that once placed in operation with a felt speed of $3100 \mathrm{ft} / \mathrm{min}(946 \mathrm{~m} / \mathrm{min})$ the roll would be turning at $743 \mathrm{rpm}$.

In addition to balancing, another critical parameter would be the natural frequency of the roll. A theory concerning the fracture of the roll was that the roll was in operation with sufficient imbalance and operating at sufficient proximity to a natural frequency of the roll that there developed an amplitude of vibration and a corresponding cyclical bending stress that resulted in the fatigue fracture observed. It would be imperative to avoid operating the roll at speeds at or near its natural frequency [4]. In an effort to explore this "natural frequency" theory, an unused roll from the same purchase order was subjected to a "ring test". A ring test is conducted by striking an object and measuring the frequency at which the object tends to vibrate. This test of the unused roll showed a first natural frequency at $640 \mathrm{rpm}$ and a second natural frequency at $1160 \mathrm{rpm}$.

An additional test was conducted on the unused roll whereby the roll was operated at various speeds and the vibrations accelerations and amplitudes were measured. The vibration peaked at a first critical speed of $650 \mathrm{rpm}$, dropped rapidly to a minimum at the balance speed of $840 \mathrm{rpm}$, and then rose rapidly as the speed approached the second critical at $1160 \mathrm{rpm}$.

Based on the results of these tests alone, it was determined that excessive vibration amplitude at an operating 
Fig. 12 Roll load diagram and corresponding moment diagram
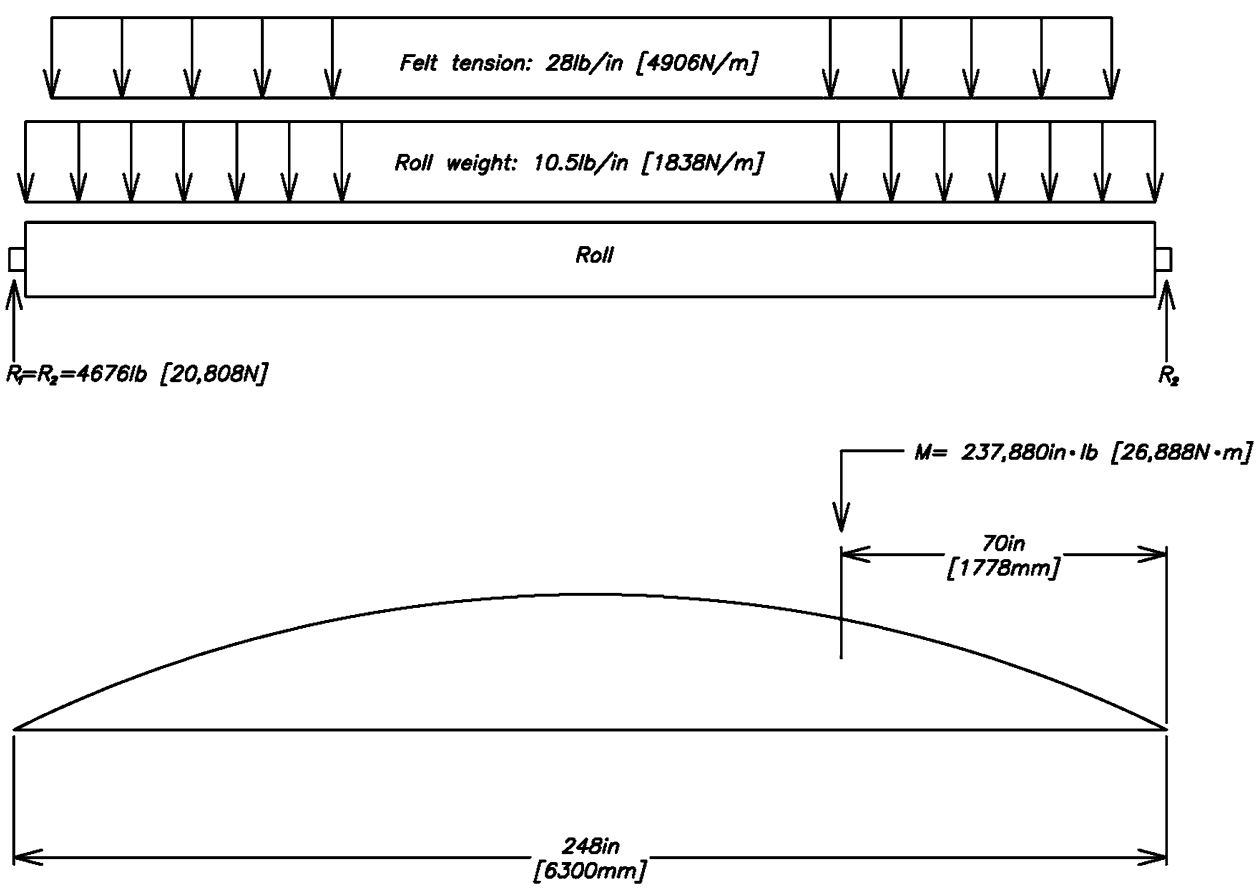

speed of $743 \mathrm{rpm}$ would not have been expected and that operation at this speed would not have been a factor in the fracture of the roll. Further, once the roll was in place and the machine operating at $3100 \mathrm{ft} / \mathrm{min}(946 \mathrm{~m} / \mathrm{min})$, the vibration of the machine was monitored. The operation of the machine would have tripped at a vibration level well below that which would have been expected in self destruction of the roll. Further still, a roll in a paper machine that is out of balance and rotating near critical will announce its unbalance and corresponding vibrating condition by sensory perception on the part of the machine operators. The known machine operating history as derived from monitoring both by instrumentation and by the sensory perception of the operators in place at the machine did not support a theory that the roll destructed due to imbalance or operation at critical speed.

\section{Analysis of the As-Manufactured Condition}

As a parallel effort in the analysis of the fracture of the roll, consideration was also given to its manufactured condition. In this regard, it was determined that the variation in the wall thickness of the pipe product used to make the roll was greater than what would have been an acceptable variation. Likewise, the compensating balance weight blocks installed were outside the normal maximum accepted weight. The integrity of the manufactured condition of the roll was therefore brought into question.

Figure 12 shows a basic model of the roll represented as a simply supported beam. The loads on the span of the beam that would subject the roll to cyclic bending stress as it rotated in place are:

(a) The weight of the roll, determined to be $10.5 \mathrm{lb} / \mathrm{in}$ (1838 N/m).

(b) The belt tension, known to be $28 \mathrm{lb} / \mathrm{in}(4906 \mathrm{~N} / \mathrm{m})$.

Shown also as part of Fig. 12 is the corresponding moment diagram, identifying the bending moment at the fracture location to be $237,880 \mathrm{lb}$-in. $(26,888 \mathrm{~N} \mathrm{~m})$. As the roll rotates, the corresponding fully reversed stress (without compensating for the variation in a roll wall thickness) would be 1770 psi $(12,204 \mathrm{kPa})$. Other contributing loads due to, say, hoop stress in a rotating cylindrical shell and the centripetal force exerted by the balancing weight on the roll wall would be negligible.

Given that the roll rotates at $743 \mathrm{rpm}$, the load cycles experienced in a single day of operation would exceed $10^{6}$ cycles. High cycle fatigue would, therefore, be involved. Classic fatigue design methodology would be suitable as an analysis procedure [5]. In this regard, the stimulus to fracture would be the fully reversed bending stress of 1770 psi $(12,204 \mathrm{kPa})$.

To estimate the resistance to fracture in fatigue, the following expression was used:

$\operatorname{Sn} \mid 10^{6}=0.5 \mathrm{Su} C_{\mathrm{L}} C_{\mathrm{D}} C_{\mathrm{S}} / K_{\mathrm{f}}$,

where $\mathrm{Snl} 10^{6}$ is the fatigue limit at $10^{6}$ cycles for plain carbon steel. $\mathrm{Su}$ is the 75,000 psi $(517,000 \mathrm{kPa})$ (as determined by testing tensile specimens cut from the roll wall). $C_{\mathrm{L}}$ is the load factor $=1.0$ (bending). $C_{\mathrm{D}}$ is the size factor $=0.75$ [diameter $>12$ in. $(305 \mathrm{~mm})] . C_{\mathrm{S}}$ is the surface finish $=0.9$ (ground surface). $K_{\mathrm{f}}$ is the fatigue 


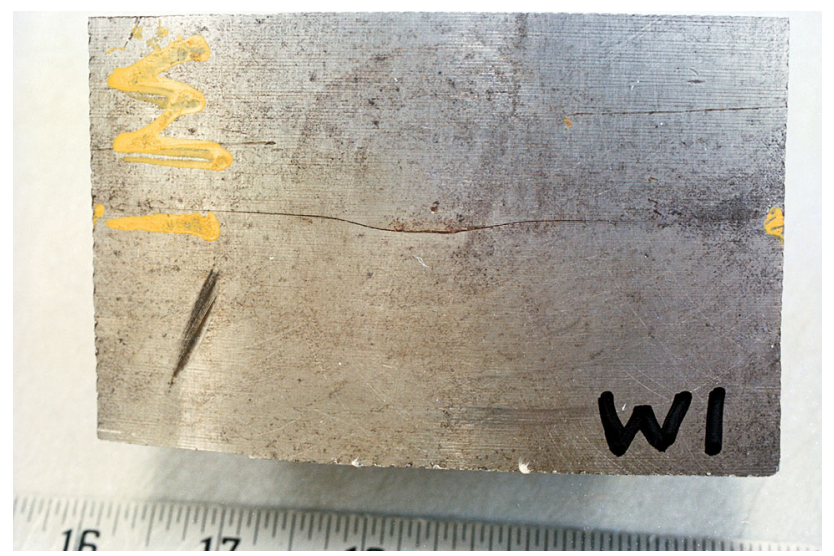

Fig. 13 Piece of roll, as removed at location of crack in roll at balance weight screw location

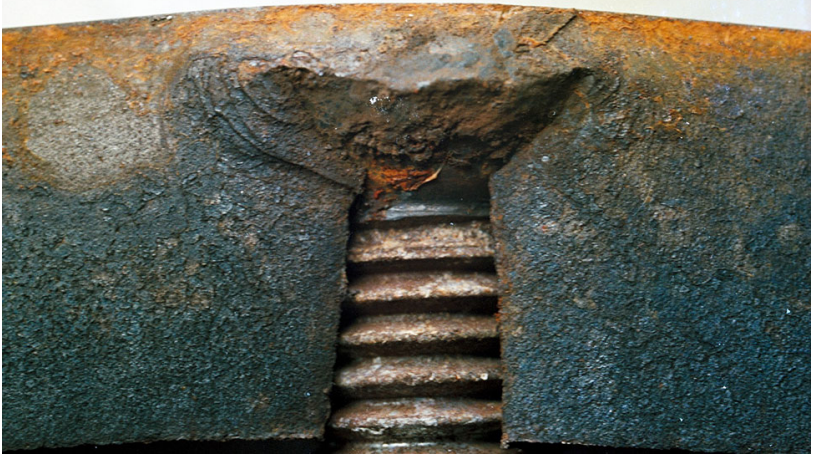

Fig. 14 Crack shown in Fig. 13 now opened to expose screw as-installed and related fatigue crack surface

stress concentration fracture. Therefore, $\operatorname{Sn} 110^{6}=25,300 /$ $K_{\mathrm{f}}$ psi $\left(174,400 / K_{\mathrm{f}} \mathrm{kPa}\right)$.

Fracture in fatigue would be predicted when the cyclic bending stress approached or exceeded the fatigue limit. Setting the cyclic bending stress equal to the fatigue limit and solving for $K_{\mathrm{f}}$ :

$1770=25,300 / K_{\mathrm{f}} \quad K_{\mathrm{f}}=14.3$.

This estimated value for the fatigue stress concentration $\left(K_{\mathrm{f}}=14.3\right)$ appeared to be high. Consideration was therefore given to the metallurgical and physical conditions that would have existed at the fracture initiation location and that would have contributed to the concentration of stress.

Reference here is to Fig. 7 which shows that the fatigue fracture of the roll initiated where a screw was installed to secure a balance weight. To better determine the manner in which this screw had been installed, a crack location away from the fracture was removed from the roll for examination. Figure 13 shows the piece of the roll removed with a

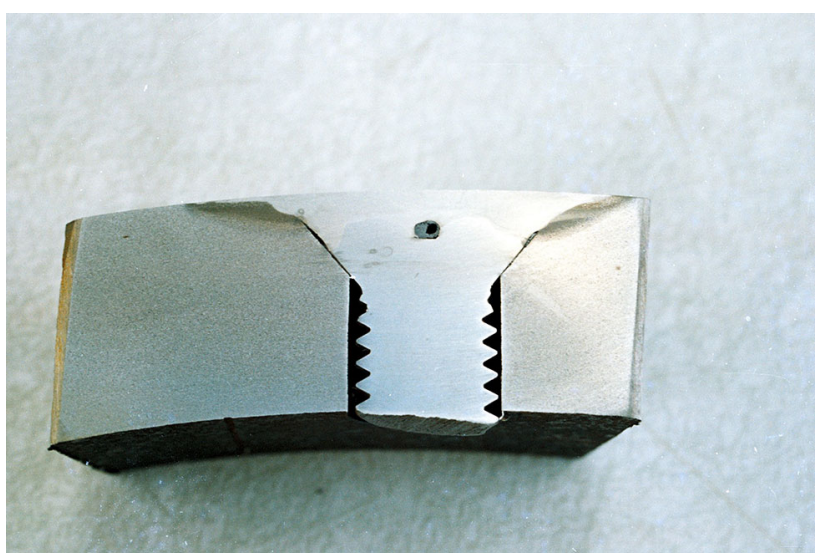

Fig. 15 Crack location shown in Fig. 14, polished and etched to reveal manner of installation of screw in detail

crack intact. Figure 14 shows the crack opened, displaying the screw in place, the weld overlaying the head of the screw, and a fatigue cracks migrating from the screw head. Figure 15 is the same location shown in Fig. 14 but now polished and etched to further reveal the manner of the assembly.

As part of the examination, the chemistry and the material microstructure of the parent metal were also examined. In this manner, the material, as a pipe product, was confirmed to comply with ASTM A106. Further, examination of the microstructure showed a localized hardened material associated with the weld heat-affected zone, as also verified by microhardness readings.

Returning to Fig. 15 and the consideration of fatigue stress concentration, $K_{\mathrm{f}}=14.3$, conditions contributing to the stress concentration at this location would be the following:

1. A hole drilled through the roll wall.

2. Reduced wall thickness.

3. A sharp-tipped notch where the weld metal overlays the screw head.

4. Localized variation in microstructure at the sharp notch at the screw head (metallurgical notch).

5. The absence of stress relief of the weld.

These considerations, taken together were determined to have resulted in a manufactured condition sufficient to create a stress concentration at the screw inset location which would then have initiated the fatigue fracture of the roll.

\section{Conclusions and Discussions}

Based on the analysis of this fracture, it was concluded as follows: 
1. The roll fractured in fatigue.

2. The fracture was not a result of excessive load created by imbalance and operation at or near a critical speed.

3. The fracture was a result of the as-manufactured condition of the roll.

4. The cause of the fracture was the manufacturer of the roll in that the manufacturer produced a defective roll having a location of high stress concentration sufficient to have initiated fracture in fatigue.

The method used to produce the roll-the use of a pipe product and the addition of balance weights to compensate for wall thickness variation-is accepted in the industry. Multiple rolls are in service that have been manufactured in this way. The procedure, however, is such that rolls such as this roll will inevitably be produced at the margin and not survive service conditions. The manner of assembly is nondeterminant.

Since the method of manufacturing has been in place over an extended time, it is unlikely that the process of drilling through the roll wall and using screws to attach balance weights would be subject to change. There is, however, a significant step that can be added to the manufacturing process that would reduce stress concentration and promote survival of such rolls_-stress relieving the plug weld location.
Another consideration is the use of seamless pipe to manufacture the roll. Seamless pipe exhibits significantly larger wall thickness variations when compared to rolled and welded pipe, such as ASTM A53. Any issues that might be associated with the pipe longitudinal weld would be offset by a more uniform wall and therefore a reduction in the amount of balance weights required.

Acknowledgments A colleague William "Bill" Harrison (now deceased) is acknowledged for having conducted the work at the site. The handwriting on Fig. 1 is Bill's. Senior Technician, Ron Windham, at the ED\&T Columbia District Office is credited for conducting all of the lab work.

\section{References}

1. ASTM A 106-14, Standard Specification for Seamless Carbon Steel Pipe for High-Temperature Service

2. W.T. Thomson, Theory of Vibration with Applications (PrenticeHall, Upper Saddle River, 1972)

3. T. Baumeister, E.A. Avallone, T. Baumeister, Mark's Standard Handbook for Mechanical Engineers, 8th edn. (McGraw-Hill, New York, 1978)

4. R.J. Roark, W.C. Young, Formulas for Stress and Strain, 5th edn. (McGraw-Hill, New York, 1975)

5. R.D. Harris, T.A. Jur, Classical Fatigue Design Techniques as a Failure Analysis Tool. J. Fail. Anal. Prev. 9, 81-87 (2009) 